\title{
ANÁLISE DA EFICIÊNCIA DO PROCESSO DE TRATAMENTO DE CORANTES PELO MÉTODO DE OXIDAÇÃO ANÓDICA
}

\author{
Marco Aurélio Mendes dos Reis \\ marcomendes91@hotmail.com \\ Eleonora Henriques Amorim de Jesus \\ Universidade Federal de Uberlândia - UFU \\ eleonoraamorim@globo.com
}

\begin{abstract}
RESUMO
O tratamento de água contaminada com compostos orgânicos é realizado por meio da coagulação química e tratamento biológico seguido de adsorção em carbono ativado, sendo métodos ineficientes para os microcontaminantes encontrados em águas de abastecimento e efluentes. A este respeito, nos últimos anos, têm sido importante intervir em diferentes níveis no tratamento, tais como rearranjo do processo, atualização de tecnologia e desenvolvimento de novas tecnologias para processos mais eficazes, tais como processos de oxidação eletroquímica. Neste trabalho, foi feito o estudo da degradação dos corantes sintéticos Ácido Vermelho 8, Ácido Azul 113 e Ácido Amarelo 17. O estudo foi realizado utilizando um volume de $200 \mathrm{ml}$ de solução a 100 ppm de corante, utilizando o anodo DDB (Diamante Dopado de Boro) e cátodo aço inox, ambos com $10 \mathrm{~cm}^{2}$ de área. $O$ tratamento eletroquímico proposto apresentou-se promissor na remoção dos corantes sintéticos utilizados.
\end{abstract}

Palavras-chave: Degradação de corantes; DDB; Oxidação eletroquímica.

\section{ANALYSIS OF COLOURS TREATMENT PROCESS EFFICIENCY BY RUST ANODIC METHOD}

\begin{abstract}
The water treatment, which it is contaminated with organic compounds, is realized by chemical coagulation and biological treatment followed by adsorption on activated carbon, but they are inefficient methods for microcontaminants from the fluvial water and effluents. In this recent years, the intervention have been important at different levels in treatment, such as the rearrangement process, updating technology and developing new technologies for more efficient processes, such as electrochemical oxidation processes. This assignment analyzed the degradation of synthetic dyes Acid Red 8, Acid Blue 113 and Acid Yellow 17. The study was realized using $200 \mathrm{ml}$ of dye solution at $100 \mathrm{ppm}$ using the BDD (Boron Doped Diamond) anode and stainless steel cathode, both with $10 \mathrm{~cm}^{2}$ of area. The proposed electrochemical treatment presented promising the removal of synthetic dyes used in this assignment.
\end{abstract}

Keywords: Color degradation; DDB; Electrochemical oxidation.

\section{INTRODUÇÃO}

Diversas indústrias como a têxtil, de produção de papel, de couro, de tingimento de cabelo entre outras, utilizam de forma extensiva os corantes sintéticos em sua linha de produção, devido a essa produção desenfreada comandada pela lei do comércio, uma quantidade imensa desses materiais tem sido lançada e tem causado uma considerável poluição no meio ambiente e consequentemente, vem trazendo sérios riscos à saúde do homem.

As indústrias que fazem uso desses materiais produzem grandes quantidades de águas residuais durante o seu processo produtivo, as quais carregam uma grande carga de corantes que não se fixaram nas superfícies dos mais diversos materiais, e por isso são eliminadas, causando uma coloração específica e nociva no efluente. Segundo Forgacs; Cserháti; Oros (2004) e MartínezHuitle; Brillas (2009) os cursos de água que recebem esta carga são afetados em relação a sua transparência, solubilidade de gases e podem apresentar propriedades carcinogênicas e 
mutagênicas. Esses mesmos autores afirmam que na indústria têxtil, $60 \%$ dos corantes utilizados são os corantes azo, em que o grupo $-\mathrm{N}=\mathrm{N}$ - é ligado a um anel aromático. Esses corantes são fortemente reativos e por isso são amplamente utilizados, além de apresentarem uma fácil aplicação e uma grande estabilidade.

O processo de oxidação anódica ou degradação eletroquímica possui a capacidade de se tornar um importante método de tratamento de efluentes, pois é bastante versátil e extremamente eficiente. Este processo atua modificando, degradando ou mineralizando compostos orgânicos por meio de diversos processos onde o único reagente envolvido é o elétron.

Isso pode ocorrer de duas formas diferentes. A primeira é quando ocorre a troca direta de elétrons entre o composto orgânico e a superfície do eletrodo e a segunda é quando acontece de forma indireta, pela intermediação de espécies eletroativas oxidantes formadas no anodo, a oxidação do resíduo. Esta segunda forma de reação acontece comumente quando o processo eletroquímico envolve a formação de radicais hidroxila $\left(\mathrm{OH}^{-}\right)$, espécie intermediária da reação de evolução de oxigênio.

Os corantes têxteis existem desde os primórdios da civilização, porém apenas os naturais. Os corantes sintéticos foram descobertos pelo químico inglês Willian $\mathrm{H}$. Pequim que em 1856 criou o primeiro corante sintético.

Os corantes sintéticos são classificados em diversos grupos, dentre eles estão os corantes azos que formam o maior grupo entre os corantes sintéticos. Seu sistema de cromóforos consiste em grupos azo (-N=N-) em associação com sistemas aromáticos e auxocromos (grupo saturado que quando ligado ao cromóforo, altera tanto o comprimento de onda como a intensidade de absorção $\left(-\mathrm{OH},-\mathrm{SO}_{3}, \mathrm{OH}, \mathrm{NH}_{2}\right.$ e $\left.\mathrm{Cl}_{2}\right)$.

A redução da cor de um corante azo está diretamente ligada a quebra da ligação $-\mathrm{N}=\mathrm{N}-$, porém, a quebra desses grupos origina grupos secundários de aminas, necessitando assim de um tratamento terciário posterior (CARVALHO et al., 2004).

A preocupação com rejeitos contendo essa classe de corantes tem crescido nos anos mais recentes, devido a suas comprovadas propriedades mutagênicas (ZANONI; GUARATINI, 2000).

As primeiras indústrias têxteis foram introduzidas no Brasil por volta de 1850, porém mesmo sendo muito antigas elas são um dos setores que mais poluem quando a composição e o volume de efluente descartado são consideráveis (ELIZALDE-GONÇÁLEZ et al., 2003).

Para Higa (2008), seu potencial poluidor de pequeno e médio porte equivale ao volume de resíduos gerados por aproximadamente 7.000 a 20.000 pessoas, considerando-se o teor de matéria orgânica.

Estes efluentes provenientes de indústrias têxteis apresentam como característica uma intensa coloração que quando presentes em ambientes aquáticos possuem a capacidade de interferir nos processos biológicos dos seres presentes, como por exemplo a fotossíntese, além de como já citado podem possuir também características carcinogênicas e/ou mutagênicas. Estudos indicam que a poluição colorida de cursos d'água começa a ser observável a concentrações acima de $1 \mathrm{mg}$ $\mathrm{L}^{-1}$ (CATANHO et al., 2006).

O tratamento destes resíduos apresenta um elevado grau de dificuldade, principalmente porque são geradas enormes quantidades desses resíduos e também porque possuem estruturas complexas comprometendo a aplicação e a eficiência dos métodos. Atualmente, a indústria têxtil de tingimento está sob considerável pressão para reduzir a cor de efluentes gerados (FERNANDES et al., 2004).

O diamante há muito atrai a cobiça humana, apresenta um imenso valor comercial e características físico-químicas únicas. É uma forma extremamente dura e cristalina do carbono, por isso é considerado o material ideal para muitas aplicações.

Há pouco descobriu-se a possibilidade da produção de filmes de diamante policristalino, material que apresenta propriedades mecânicas e eletrônicas extremamente semelhantes ao diamante natural.

Estes filmes vêm sendo aplicados em diversos ramos do conhecimento, principalmente em uma área relativamente nova, iniciada em meados da década de 1980, conhecida como eletroquímica 
de eletrodos de diamante, a partir desta data os estudos eletroquímicos e o número de laboratórios envolvidos com este trabalho tem aumentado significativamente.

Os primeiros artigos foram dedicados à melhoria da tecnologia para fabricação de realização de filmes finos e para compreender melhor a relação entre os semicondutores e propriedades estruturais de diamantes e suas características eletroquímicas, (PANIZZA; CERISOLA, 2005).

Alguns autores (Panizza; Cerisola 2005; Martínez-Huitle; Ferro, 2006) afirmam que os eletrodos de DDB passaram a ter destaque, pois possuem tecnologia relevante para a oxidação anódica, que abrange particularidades de baixa adsorção em sua superfície uma superfície, de impressionante imutabilidade à corrosão, ainda que em meios com pH altamente baixo e sobre potencial de $\mathrm{O}_{2}$ intensamente elevado. Desta forma, estes artifícios poderão ser usados no tratamento de efluentes em alta proporção. (MARTíNEZ-HUITLE; FERRO, 2006).

\section{METODOLOGIA}

Os ensaios laboratoriais do presente trabalho foram realizados no laboratório de físico química da Universidade da Beira Interior localizado no município de Covilhã em Portugal.

Preparo das soluções

As soluções sintéticas foram preparadas dissolvendo os corantes em pó em água destilada contendo sulfato de sódio $\left(\mathrm{Na}_{2} \mathrm{SO}_{4}\right) 0,25 \mathrm{~mol} \mathrm{~L}^{-1}$, pois este sal apresenta boa condutividade elétrica em solução aquosa. As concentrações de corantes usadas foram de $100 \mathrm{ppm}$ para todos os experimentos.

Foram realizados os cálculos para $100 \mathrm{ppm}$ de corante, o qual forneceu o valor de $25 \mathrm{mg}$ de corante para $250 \mathrm{ml}$ de solução. Inicialmente foram pesados $25 \mathrm{~g}$ para o Ácido vermelho $8,25 \mathrm{~g}$ para o Ácido Amarelo 17 e $25 \mathrm{~g}$ para o Ácido Azul 113, após essas medições os corantes foram diluídos em água destilada e sulfato de sódio, atingindo em um balão volumétrico, o volume de 250 $\mathrm{ml}$, após a total diluição, a solução foi levada a um becker de $200 \mathrm{ml}$ onde havia uma barra de agitação magnética.

Após o preparo, as barras de DDB e aço inox foram conectadas ao gerador de corrente sendo afixados aos polos positivo e negativo do mesmo, respectivamente. Ligando todas as fiações as placas foram imersas no becker contendo a solução e foi ligada a corrente, sendo esta regulada em 0,3 Amperes.

Para o estudo em questão determinou-se as análises do Carbono Orgânico Total (TOG), carbono orgânico e carbono inorgânico (IC), Demanda Química de Oxigênio (DQO) e absorbância das amostras determinando assim a concentração de poluentes.

\section{Metodologia para a remoção da cor}

O método de espectrofotometria nada mais é do que um feixe de luz branca policromática incidindo em um prisma e quando isso ocorre, a luz branca se separa e se divide em diferentes cores em diferentes comprimentos de onda. O comprimento de onda de 380 a $780 \mathrm{~nm}$ é chamado de faixa do visível.

Esta região é utilizada na determinação de inúmeras substâncias que formam soluções coloridas, porém no estudo em questão foi utilizada a faixa compreendida entre 200 e $800 \mathrm{~nm}$. A remoção da cor foi analisada em um espectrofotômetro usando um espectrofotômetro UV 1800 Shimadzu e acompanhada pelo decréscimo de medição de absorbância.

Para o experimento foi retirada uma amostra de um (1) $\mathrm{ml}$ da solução total, esta amostra foi transferida ao frasco receptor do aparelho que armazena um volume máximo de 1,5 ml.

A amostra inicial de um $1 \mathrm{ml}$ foi diluída em $1 \mathrm{ml}$ de água destilada, o receptor do aparelho foi inicialmente lavado com água destilada e posteriormente com a solução a ser analisada, ficando assim pronto para receber a amostra a ser examinada. Após a lavagem, a cubeta foi inserida dentro do aparelho e foi iniciada a leitura dos mesmos. 
O primeiro passo foi o de plotar as curvas de calibração dos três corantes, esta curva foi traçada através dos espectros das diferentes concentrações dos corantes (Figuras 1, 2 e 3) e a partir dessas Figuras, foi possível traçar a reta de concentração dos três corantes (Figuras 4, 5, 6 e 7).

Figura 1 - Curva de absorbância por concentração do Ácido Vermelho 8 (AR8)

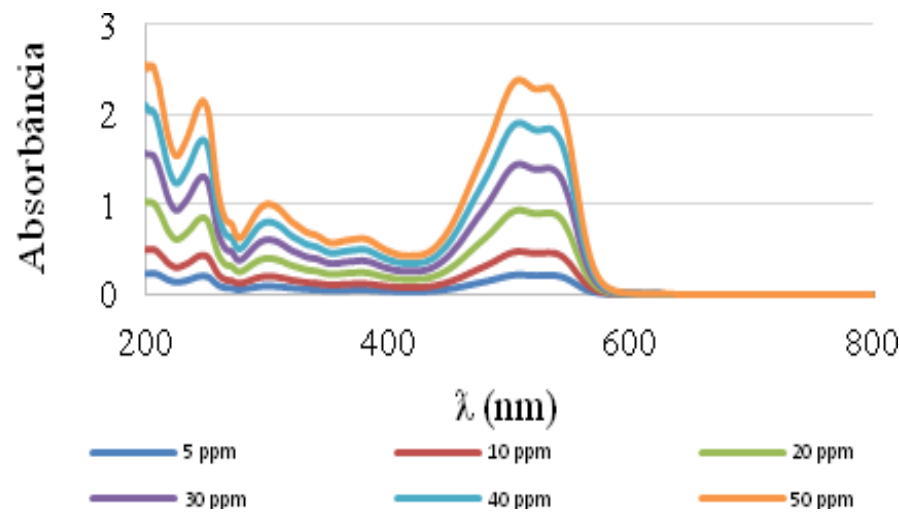

Fonte - Elaborado pelo autor

Figura 2 - Curva de absorbância por concentração do Ácido Azul (AB 113)

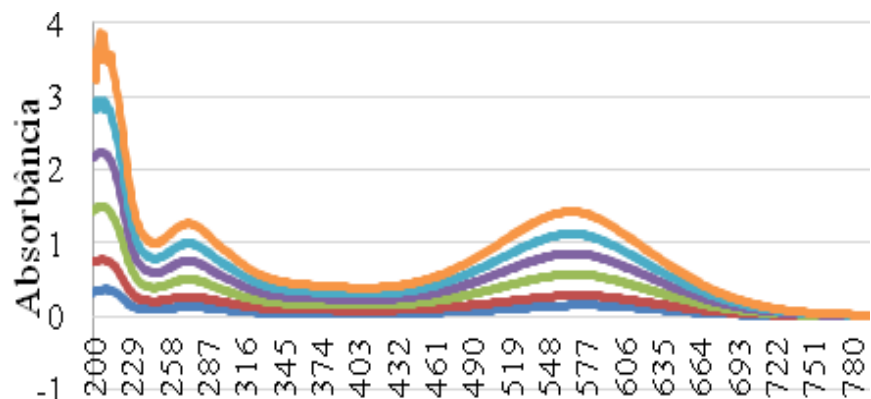

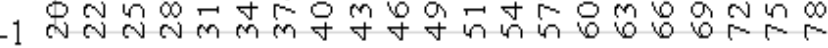

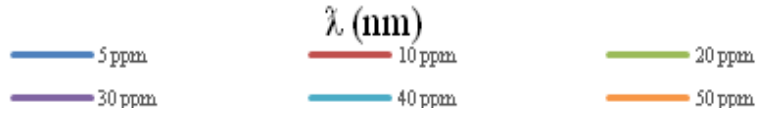

Fonte - Elaborado pelo autor

Figura 3 - Curva de absorbância por concentração do Ácido Amarelo 17 (AY 17)

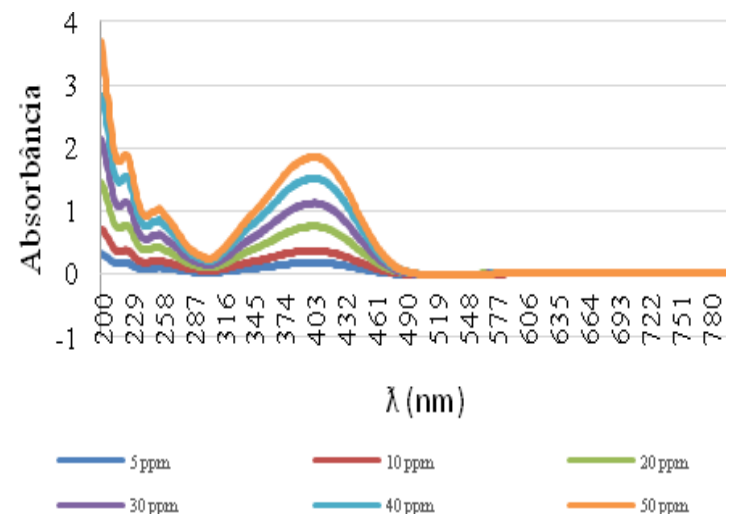

Fonte: Elaborado pelo autor 
O corante ácido vermelho 8 apresenta uma particularidade pois apresenta dois picos de absorbância, $508 \mathrm{~nm}$ e $532 \mathrm{~nm}$, necessitando assim de uma reta de concentração para o primeiro pico (Figura 4) e uma reta de concentração para o segundo pico (Figura 5). Já os demais corantes apresentam apenas um pico de absorbância, sendo para o ácido azul 113 de $566 \mathrm{~nm}$ e para o ácido amarelo $17 \mathrm{de} 400 \mathrm{~nm}$.

Figura 4 - Reta de concentração do Ácido Vermelho 8 a 508 nm.

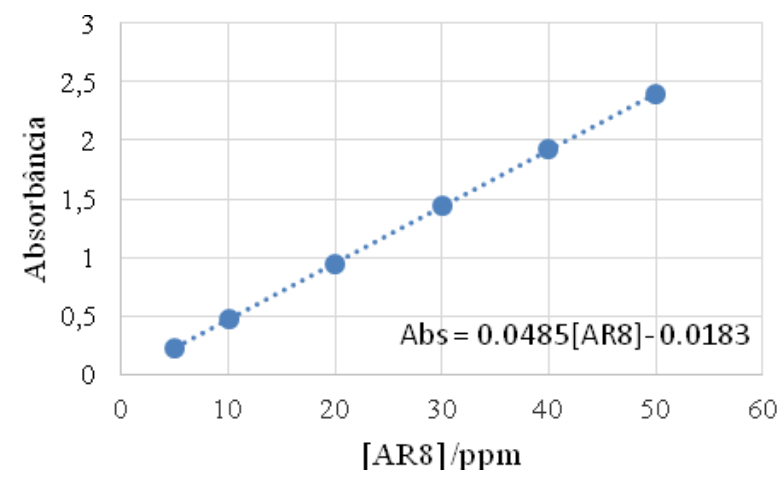

Fonte - Elaborado pelo autor

Figura 5 - Reta de concentração do Ácido Vermelho 8 a 532 nm

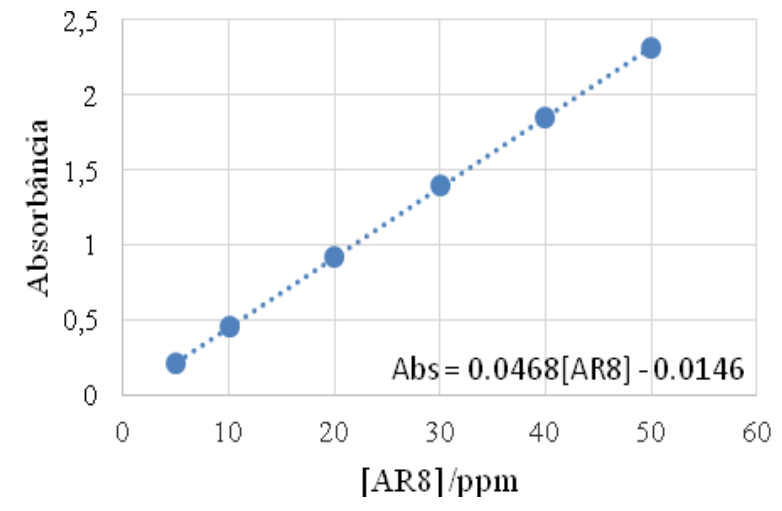

Fonte - Elaborado pelo autor

Figura 6 - Reta de concentração do Ácido Azul a 565 nm

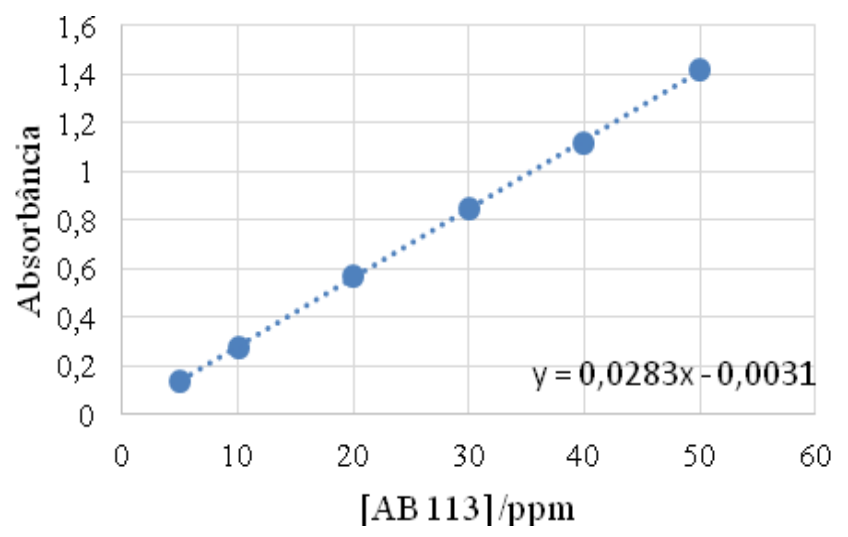

Fonte - Elaborado pelo autor 
Figura 7 - Reta de concentração do Ácido Amarelo 17 a 403 nm

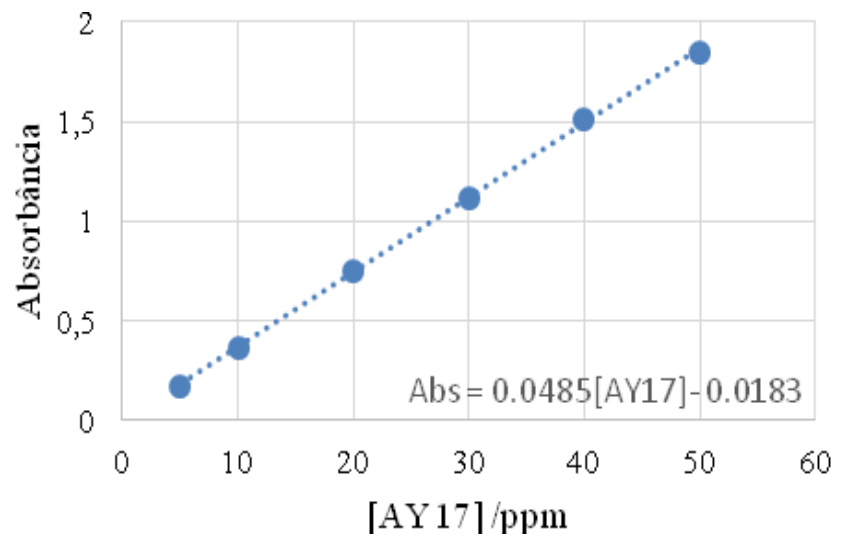

Fonte - Elaborado pelo autor

\section{METODOLOGIA PARA A ANÁLISE DO CARBONO}

A análise da matéria carbonácea é um indicador de poluição ambiental, e sua determinação é exigida pela legislação ambiental vigente, CONAMA № 357/05 e CONAMA № 430/2011. É de fundamental relevância para monitoramento e controle ambiental de águas e de efluentes. $O$ Analisador de Carbono Orgânico Total (TOC) utilizado neste trabalho foi o TOC-V csh Shimadzu. Este equipamento mede a quantidade de Carbono Total (TC) e Carbono Inorgânico (IC) da amostra. Ressalta-se que o TOC é dado pela subtração de TC e IC.

O trabalho teve início com a verificação da quantidade de carbono presente na amostra original e com a verificação da diluição melhor a ser feita. Portanto foram testadas duas diluições, a 1:2 e a 1:5, por fim verificou-se que a ideal quando comparávamos com o volume do frasco para amostragem seria a diluição de 1:3.

O processo de análise consistia na retirada de $10 \mathrm{ml}$ da amostra inicial, sendo que, eram direcionados $5 \mathrm{ml}$ para os tubos de ensaio destinados a análise do carbono. Para essas análises, foi realizada uma diluição de 1 para 3 sendo $5 \mathrm{ml}$ de amostra e $10 \mathrm{ml}$ de água destilada. Após a separação, os tubos foram fechados com papel alumínio e com tampa específica do tubo, em seguida as amostras eram inseridas no aparelho.

Metodologia para se determinar a demanda química de oxigênio (DQO)

A obtenção da demanda química de oxigênio (DQO) determina o valor do oxigênio necessário para oxidar a matéria orgânica presente na amostra por meio de substâncias químicas que são oxidantes fortes.

O método utilizado foi o Padrão Refluxo Aberto, que consiste em descobrir a DQO por meio da titulação da amostra. Esse método consiste na titulação por meio do sulfato ferroso amoniacal $\left(\mathrm{Fe}\left(\mathrm{NH}_{4}\right)_{2}\left(\mathrm{SO}_{4}\right)_{2} .6 \mathrm{H}_{2} \mathrm{O}\right)$, da quantidade de dicromato de potássio resultante do processo de oxidação química na amostra por meio de uma quantidade específica de dicromato de potássio $\left(\mathrm{K}_{2} \mathrm{Cr}_{2} \mathrm{O}_{7}\right)$ e ácido sulfúrico $\left(\mathrm{H}_{2} \mathrm{SO}_{4}\right)$, pois a medida do consumo de oxigênio ocorrido durante a oxidação química da matéria orgânica é proporcional ao dicromato de potássio consumido.

$\mathrm{Na}$ oxidação da matéria orgânica por dicromato de potássio em meio ácido, ocorre a produção de dióxido de carbono, água, além de outros elementos orgânicos que também sofrem oxidação, conforme a Equação (1).

$2 \mathrm{KC}_{8} \mathrm{H}_{5} \mathrm{O}_{4}(\mathrm{aq})+10 \mathrm{~K}_{2} \mathrm{Cr}_{2} \mathrm{O}_{7}(\mathrm{aq})+41 \mathrm{H}_{2} \mathrm{SO}_{4}(\mathrm{aq}) \rightarrow 16 \mathrm{CO}_{2}(\mathrm{~g})+\mathrm{H}_{2} \mathrm{O}_{(l)}+10 \mathrm{Cr}_{2}\left(\mathrm{SO}_{4}\right)_{3}(\mathrm{aq})+11 \mathrm{~K}_{2} \mathrm{SO}_{4}(\mathrm{aq})(1)$

Inicialmente foram preparadas soluções dos corantes com valor de diluição de 1:1 com objetivo de se determinar os valores de DQO das amostras originais (Tabela 1). 
Tabela 1 - DQO para caracterização das amostras.

\begin{tabular}{|c|c|c|c|c|}
\hline Amostra & Diluição (ml) & Titulação & Média & $D Q O$ \\
\hline $\begin{array}{c}\text { Amarelo } \\
\text { (AY17) }\end{array}$ & $1 / 1$ & $3614 \quad 3712$ & 3663 & 90 \\
\hline $\begin{array}{c}\text { Azul } \\
\text { (AB113) }\end{array}$ & $1 / 1$ & $\begin{array}{ll}3386 & 3538\end{array}$ & 3462 & 145 \\
\hline $\begin{array}{c}\text { Vermelho } \\
\text { (AR8) }\end{array}$ & $1 / 1$ & $\begin{array}{ll}3478 \quad 3460\end{array}$ & 3469 & 143 \\
\hline
\end{tabular}

Fonte - Elaborado pelo autor

Posteriormente foram preparadas as amostras para as análises. As amostras do experimento foram retiradas de hora em hora durante um período de seis horas obtendo então sete amostras, contando com a inicial. Estas amostras continham o volume de $10 \mathrm{ml}$ sendo que 1,5 desta solução é destinada a análise do DQO. Utilizando uma pipetadora eram inseridos em tubos de ensaio próprios para a análise de DQO 1,5 ml de amostra, $2 \mathrm{ml}$ de ácido sulfúrico e 1 $\mathrm{ml}$ de solução de dicromato de potássio, após a adição de todas as substâncias, os tubos foram fechados e levados ao agitador, após serem agitados, todos os tubos foram levados ao digestor onde permaneceram aquecidos durante duas horas. Após o aquecimento e resfriamento, as amostras eram levadas a titulação onde foram transferidas para elemayers.

Após a transferência foram adicionadas duas gotas de indicador ferroína à amostra, após a adição a amostra era direcionada ao titulador eletrônico onde recebeu uma barra de agitação magnética e iniciou-se a titulação, usando como indicador a ferroína.

O valor encontrado no titulador corresponde ao valor da DQO da amostra, sendo retirada do digestor, apresenta coloração amarelada, ao se adicionar o titulante a amostra altera a sua tonalidade para verde e posteriormente para vermelho, sendo este o ponto de viragem correto.

\section{RESULTADOS E DISCUSSÃO}

No processo citado a reação de oxidação dos poluentes trata-se de uma reação de oxidação, na qual a molécula de corante reage com o oxigênio resultante do processo de quebra da molécula de água pelos na superfície do ânodo de DDB, em uma reação de combustão, gerando como principais produtos $\mathrm{O} \mathrm{CO}_{2}, \mathrm{H}_{2} \mathrm{O}$ e no caso dos corantes azo citados, o $\mathrm{NH}_{4}{ }^{+}$como exemplificado nas equações não balanceadas 2 referente ao ácido vermelho 8,3 referente ao ácido amarelo 17 e 4 referente ao ácido azul 113.

$$
\begin{aligned}
& \mathrm{C}_{18} \mathrm{H}_{14} \mathrm{~N}_{2} \mathrm{Na}_{2} \mathrm{O}_{7} \mathrm{~S}_{2}+\mathrm{O}_{2} \rightarrow \mathrm{CO}_{2}+\mathrm{H}_{2} \mathrm{O}+\mathrm{Na}^{+}+\mathrm{SO}_{4}^{2-}+\mathrm{NH}^{4+} \\
& \mathrm{C}_{16} \mathrm{H}_{10} \mathrm{CL}_{2} \mathrm{~N}_{4} \mathrm{Na}_{2} \mathrm{O}_{7} \mathrm{~S}_{2}+\mathrm{O}_{2} \rightarrow \mathrm{CO}_{2}+\mathrm{H}_{2} \mathrm{O}+\mathrm{Na}^{+}+\mathrm{SO}_{4}^{2-}+\mathrm{NH}^{4+}+\mathrm{CL}^{-} \\
& \mathrm{C}_{32} \mathrm{H}_{21} \mathrm{~N}_{5} \mathrm{Na}_{2} \mathrm{O}_{6} \mathrm{~S}_{2}+\mathrm{O}_{2} \rightarrow \mathrm{CO}_{2}+\mathrm{H}_{2} \mathrm{O}+\mathrm{Na}^{+}+\mathrm{SO}_{4}{ }^{2-}+\mathrm{NH}^{4+}+\mathrm{e}^{-}
\end{aligned}
$$

Com base nos materiais e métodos utilizados foi possível chegar aos seguintes resultados.

Remoção da cor

O processo de degradação eletroquímica executado apresentou os resultados a seguir de acordo com a especificação de cada um, porém de maneira geral todos os corantes e o material resultante da mistura entre eles apresentou uma remoção de cor extremamente considerável, atingindo remoções que dificilmente são alcançadas por meio de outro tipo de tratamento.

Este processo de remoção da cor se deve, quando trabalhamos com corantes azo, pelo processo de quebra deste grupo, presente na estrutura do corante.

Ácido Vermelho 8, $100 \mathrm{ppm}+5 \mathrm{~g} / \mathrm{L} \mathrm{Na}_{2} \mathrm{SO}_{4}$ 
Foi constatado no ácido vermelho 8 que a aplicação do método para a remoção da cor se mostrou extremamente eficiente pois foi conseguido sair de uma condição inicial de 45,14 ppm a $508 \mathrm{~nm}$ e $44,59 \mathrm{ppm}$ a $532 \mathrm{mn}$ e chegar a 0,40 e 0,33 respectivamente, calculados a partir das fórmulas 5 e 6 para sua respectiva absorbância, o que representou uma redução de 99,11 $\%$ e de 99,26 \% respectivamente, de acordo com a Tabela 2. O ácido vermelho 8 apresenta dois picos de absorbância, sendo assim as análises ocorreram tanto a 508 quanto a $532 \mathrm{~nm}$.

$$
\begin{array}{ll}
508 \mathrm{~nm} & A b s=0.0485[A R 8]-0.0183 \\
532 \mathrm{mn} & A b s=0.0468[A R 8]-0.0146
\end{array}
$$

Por meio da análise da Figura 1 podemos visualizar a curva dos espectros deste ácido, nesta Figura ficou evidenciada a diminuição da concentração ao longo das seis horas de experimento.

Tabela 2 - Relação de absorbância por concentração do Ácido Vermelho 8.

\begin{tabular}{c|c|c|c|c}
\hline Tempo /h & Absorbância 508 nm & [] / ppm & Absorbância 532 nm & [] / ppm \\
\hline $0(\mathrm{R} 0)$ & 2,171 & 45,14 & 2,072 & 44,59 \\
\hline $1(\mathrm{R} 1)$ & 1,076 & 22,56 & 1,038 & 22,49 \\
\hline $2(\mathrm{R} 2)$ & 0,510 & 10,89 & 0,492 & 10,82 \\
\hline $3(\mathrm{R} 3)$ & 0,207 & 4,65 & 0,200 & 4,59 \\
\hline $4(\mathrm{R} 4)$ & 0,068 & 1,78 & 0,067 & 1,74 \\
\hline $5(\mathrm{R} 5)$ & $-0,004$ & 0,29 & $-0,005$ & 0,21 \\
\hline $6(\mathrm{R} 6)$ & 0,001 & 0,40 & 0,001 & 0,33 \\
\hline & \multicolumn{2}{|c|}{ Fonte - Elaborado pelo autor }
\end{tabular}

Figura 8 - Absorbância do Ácido Vermelho 8.

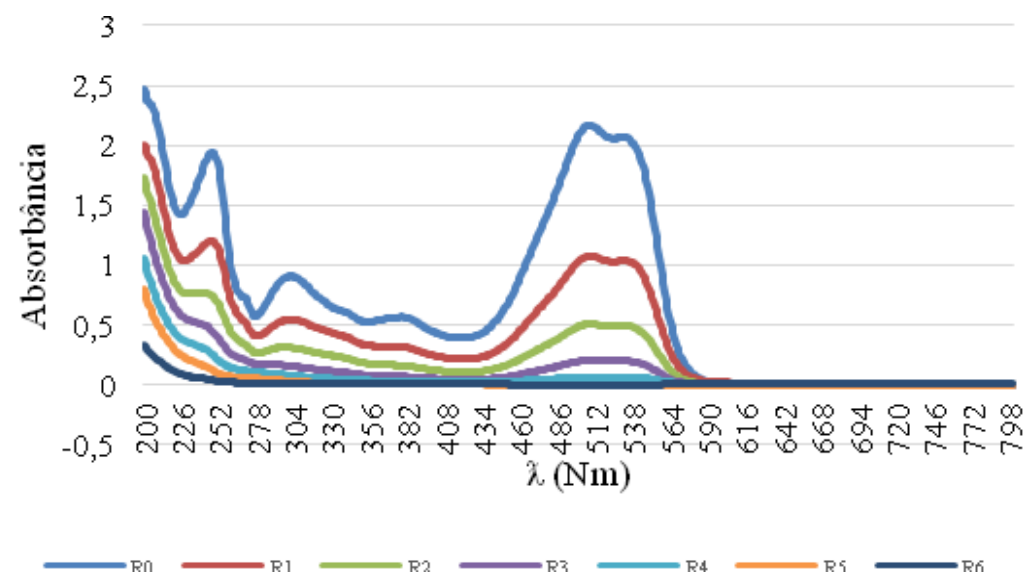

Fonte - Elaborado pelo autor

Ácido Azul 113, $100 \mathrm{ppm}+5 \mathrm{~g} / \mathrm{L} \mathrm{Na}_{2} \mathrm{SO}_{4}$

No corante Ácido Azul 113 a concentração sofreu, de acordo com a Tabela 3, uma redução de $99,57 \%$. Estes valores de concentração foram obtidos quanto substituímos os valores da absorbância obtidos na Equação 7 obtida através da reta de concentração (Figura 5).

$$
\text { Abs }=0,0283[A B 113]-0,0031
$$

Portanto, foi comprovada uma elevada eficiência do processo, a cor do sistema no final do ciclo de seis horas se mostrou ao olho humano pouco perceptível, porém por meio da Figura 9 é possível visualizar a curva de decaimento da concentração deste corante ao passar das horas, comprovando a queda. 
Tabela 3 - Relação de absorbância por concentração do Ácido Azul 113.

\begin{tabular}{ccc}
\hline Tempo / h & Abs (565 nm) & [] / ppm \\
\hline 0 (B0) & 0,926 & 32,83 \\
1 (B1) & 0,621 & 22,05 \\
2 (B2) & 0,389 & 13,86 \\
3 (B3) & 0,186 & 6,68 \\
4 (B4) & 0,069 & 2,55 \\
5 (B5) & 0,021 & 0,85 \\
6 (B6) & 0,001 & 0,14 \\
\hline
\end{tabular}

Fonte - Elaborado pelo autor

Figura 9 - Absorbância do Ácido Azul 113

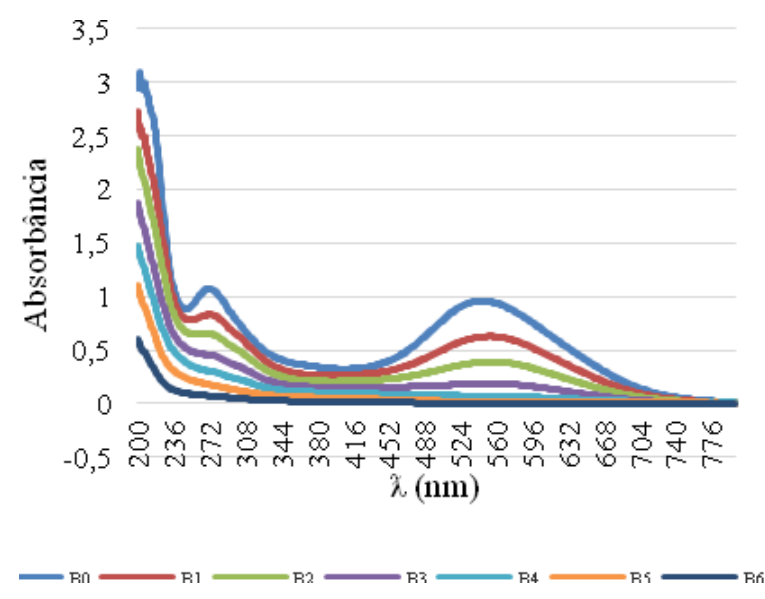

Fonte - Elaborado pelo autor

Ácido Amarelo 17, 100 ppm + $5 \mathrm{~g} / \mathrm{L} \mathrm{Na}_{2} \mathrm{SO}_{4}$

O Ácido Amarelo apresentou uma redução de $98,42 \%$ na sua concentração, seguindo assim como os corantes azul e vermelho, uma eficiência extremamente positiva, como descrito na Tabela 4, a concentração passou de $38,01 \mathrm{ppm}$ a $0,60 \mathrm{ppm}$, calculados a partir da Equação $8 \mathrm{e}$ a partir do descrito na Figura 10, podemos visualizar o decaimento da concentração do corante ao longo do procedimento experimental, esta queda comprova a quebra dos grupos azo inicialmente presentes no corante.

$$
A b s=0.0485[A Y 17]-0.0183
$$

Tabela 4 - Relação de absorbância por concentração do Ácido Amarelo 17.

\begin{tabular}{ccc}
\hline Tempo / $\mathbf{h}$ & Abs 403 nm & [] / ppm \\
\hline 0 (Y0) & 1,825 & 38,01 \\
1 (Y1) & 0,801 & 16,89 \\
2 (Y2) & 0,275 & 6,05 \\
3 (Y3) & 0,100 & 2,44 \\
4 (Y4) & 0,024 & 0,87 \\
5 (Y5) & 0,005 & 0,48 \\
6 (Y6) & 0,011 & 0,60 \\
\hline
\end{tabular}

Fonte - Elaborado pelo autor 
Figura 10 - Absorbância do Ácido Amarelo 17.

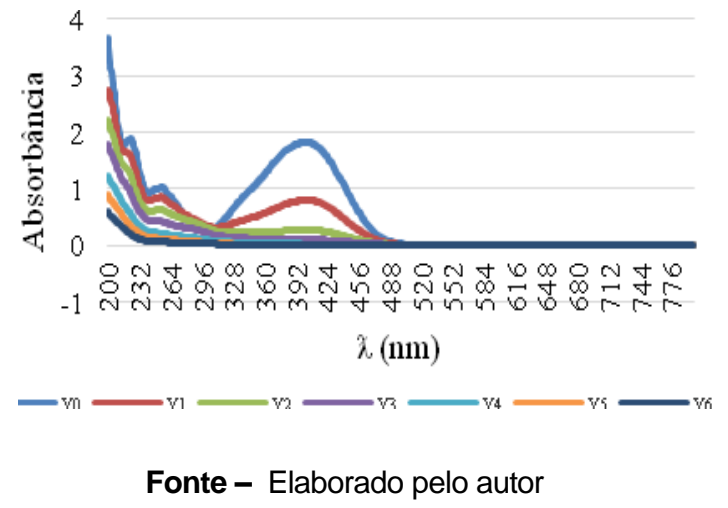

Mistura (100 ppm AR8 + 100 ppm AB113 + 100 ppm AY17) + $5 \mathrm{~g} / \mathrm{L} \mathrm{Na}_{2} \mathrm{SO}_{4}$

Na solução de mistura dos corantes os valores percentuais de remoção da concentração dos corantes se mostrou mais discreta (Tabela 5), sendo na zona dos $403 \mathrm{~nm} 95,71 \%, 508 \mathrm{~nm}$

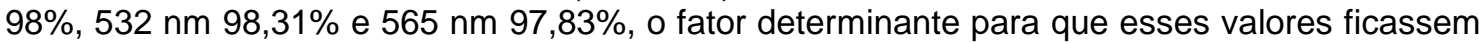
ligeiramente abaixo da remoção individual se dá em função da concentração na solução ser maior, dificultando a remoção das partículas contaminantes, porém mesmo com essa dificuldade a remoção se mostrou eficiente (Figura 11).

Tabela 5 - Relação de absorbância por concentração da Mistura.

\begin{tabular}{ccccccccc}
\hline $\begin{array}{c}\text { Tempo / } \\
\mathbf{h}\end{array}$ & $\begin{array}{c}\mathbf{A b s ~ 4 0 3} \\
\mathbf{n m}\end{array}$ & $\begin{array}{c}{[] /} \\
\mathbf{p p m}\end{array}$ & $\begin{array}{c}\mathbf{A b s} \mathbf{5 0 8} \\
\mathbf{n m}\end{array}$ & $\begin{array}{c}{[] /} \\
\mathbf{p p m}\end{array}$ & $\begin{array}{c}\mathbf{A b s} \mathbf{5 3 2} \\
\mathbf{n m}\end{array}$ & $\begin{array}{c}{[] /} \\
\mathbf{p p m}\end{array}$ & $\begin{array}{c}\text { Abs 565 } \\
\mathbf{n m}\end{array}$ & $\begin{array}{c}{[] /} \\
\mathbf{p p m}\end{array}$ \\
\hline 0 (M0) & 2,673 & 55,49 & 3,037 & 63,00 & 3,088 & 66,29 & 1,472 & 52,12 \\
1 (M1) & 1,689 & 35,20 & 1,641 & 34,21 & 1,664 & 35,87 & 0,845 & 29,97 \\
2 (M2) & 1,081 & 22,67 & 0,905 & 19,04 & 0,924 & 20,06 & 0,533 & 18,94 \\
3 (M3) & 0,655 & 13,88 & 0,449 & 9,64 & 0,455 & 10,03 & 0,281 & 10,04 \\
4 (M4) & 0,372 & 8,05 & 0,181 & 4,11 & 0,173 & 4,01 & 0,102 & 3,71 \\
5 (M5) & 0,188 & 4,25 & 0,075 & 1,92 & 0,067 & 1,74 & 0,04 & 1,52 \\
6 (M6) & 0,097 & 2,38 & 0,043 & 1,26 & 0,038 & 1,12 & 0,029 & 1,13 \\
\hline
\end{tabular}

Fonte - Elaborado pelo autor

Figura 11 - Absorbância da mistura

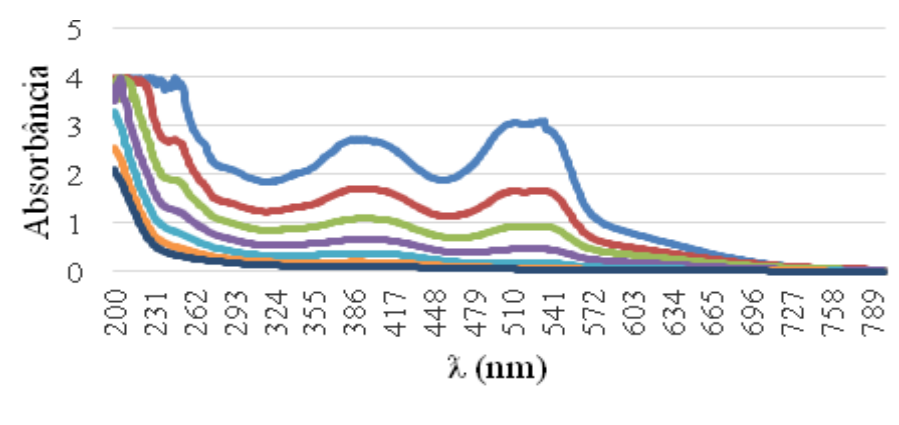

Fonte - Elaborado pelo autor 
Análise do carbono

Ácido Vermelho 8, $100 \mathrm{ppm}+5 \mathrm{~g} / \mathrm{L} \mathrm{Na}_{2} \mathrm{SO}_{4}$

Utilizando-se do método descrito avaliou-se a remoção do carbono na amostra de corante ácido vermelho 8 (Tabela 6). Utilizando o fator de diluição 3 nota-se que o carbono total (TC) da amostra sofreu ao longo do ensaio uma redução considerável. Também ficou evidente que 0 carbono inorgânico (IC) aumentou discretamente, indicando que ao longo do ensaio alguma substância orgânica se converteu em inorgânica, porém quando avaliamos o carbono orgânico total, vimos que ocorreu uma drástica redução, mostrando que ocorreu a conversão de sustâncias carbônicas em dióxido de carbono, a redução de Carbono Orgânico Total (TOC) atingiu os $96 \%$ neste ácido.

A variação de carbono nas amostras se deve pela conversão do carbono orgânico presente nos corantes por formas voláteis como o $\mathrm{CO}_{2}$ (Equações 2, 3 e 4) e inorgânicos, fazendo com que o valor de carbono inorgânico aumente sensivelmente.

Tabela 6 - Relação de carbono da amostra Ácido Vermelho 8

\begin{tabular}{|c|c|c|c|c|c|}
\hline $\begin{array}{l}\text { Fator de } \\
\text { diluição }\end{array}$ & $\mathrm{TC}^{1}$ & $\begin{array}{c}\text { TC } \\
\text { final }^{2}\end{array}$ & $\mathrm{IC}^{3}$ & IC final ${ }^{4}$ & $\begin{array}{c}\text { TOC } \\
\text { final } \\
5\end{array}$ \\
\hline 3 & 9,749 & 29,2 & 0,3325 & 1,00 & 28,2 \\
\hline 3 & 7,585 & 22,8 & 0,8047 & 2,41 & 20,3 \\
\hline 3 & 5,613 & 16,8 & 0,7962 & 2,39 & 14,5 \\
\hline 3 & 4,111 & 12,3 & 0,8581 & 2,57 & 9,8 \\
\hline 3 & 3,621 & 10,9 & 0,876 & 2,63 & 8,2 \\
\hline 3 & 6,283 & 18,8 & 0,9304 & 2,79 & 16,1 \\
\hline \multirow[t]{3}{*}{3} & 1,382 & 4,1 & 0,9935 & 2,98 & 1,2 \\
\hline & & & & $\begin{array}{c}\text { Remoção } \\
/ \mathrm{mg} \mathrm{L}^{-1}\end{array}$ & 27 \\
\hline & & & & $\begin{array}{c}\text { Remoção } \\
/ \%\end{array}$ & 96 \\
\hline
\end{tabular}

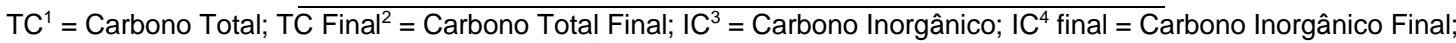
TOC $^{5}=$ Carbono Orgânico Total.

Fonte - Elaborado pelo autor

Ácido Azul 113, $100 \mathrm{ppm}+5 \mathrm{~g} / \mathrm{L} \mathrm{Na}_{2} \mathrm{SO}_{4}$

A análise do carbono no Ácido Azul evidenciou que neste a remoção se mostrou baixa quando comparado com os outros em valores percentuais, porém se compararmos em valores efetivos a remoção atingiu níveis consideráveis pois foi saído de uma condição inicial onde se tinha 34,86 e chegou a 4,77 , removendo uma quantidade de quase $30 \mathrm{mg} \cdot \mathrm{L}^{-1}$ (Tabela 7 ).

Tabela 7 - Relação de carbono da amostra Ácido Azul 113.

\begin{tabular}{|c|c|c|c|c|c|}
\hline Fator de diluição & $\mathrm{TC}^{1}$ & TC final ${ }^{2}$ & $\mathrm{IC}^{3}$ & IC final ${ }^{4}$ & TOC final ${ }^{5}$ \\
\hline 3 & 11,9 & 35,7 & 0,2767 & 0,83 & 34,8699 \\
\hline 3 & 10,87 & 32,61 & 1,231 & 3,69 & 28,917 \\
\hline 3 & 9,015 & 27,045 & 1,454 & 4,36 & 22,683 \\
\hline 3 & 7,466 & 22,398 & 1,305 & 3,92 & 18,483 \\
\hline 3 & 5,431 & 16,293 & 1,165 & 3,50 & 12,798 \\
\hline 3 & 4,989 & 14,967 & 0,8211 & 2,46 & 12,5037 \\
\hline \multirow[t]{3}{*}{3} & 2,391 & 7,173 & 0,8005 & 2,40 & 4,7715 \\
\hline & & & & Remoção / mg L-1 & 30 \\
\hline & & & & Remoção / \% & 86 \\
\hline \multicolumn{6}{|c|}{$\begin{array}{l}\text { TC }^{1}=\text { Carbono Total; TC Final }\left.\right|^{2}=\text { Carbono Total Final; IC }{ }^{3}=\text { Carbono Inorgânico; IC }{ }^{4} \text { final = Carbono Inorgânico Fina } \\
\text { TOC }^{5}=\text { Carbono Orgânico Total. }\end{array}$} \\
\hline \multicolumn{6}{|c|}{ Fonte - Elaborado pelo autor } \\
\hline
\end{tabular}


Ácido Amarelo 17, 100 ppm + $5 \mathrm{~g} / \mathrm{L} \mathrm{Na}_{2} \mathrm{SO}_{4}$

A amostragem no Ácido Amarelo 17 se mostrou satisfatória, este ácido apresentou um valor de remoção de $96 \%$ (Tabela 8), representando um valor de remoção em $\mathrm{mg} \mathrm{L}^{-1}$ discreto de apenas 19. Os valores de carbono inorgânico mostraram uma pequena elevação, assim como os ácidos anteriores.

Tabela 8 -Relação de carbono da amostra Ácido Amarelo 17.

\begin{tabular}{|c|c|c|c|c|c|}
\hline $\begin{array}{l}\text { Fator de } \\
\text { diluição }\end{array}$ & $\mathrm{TC}^{1}$ & $\begin{array}{c}\text { TC } \\
\text { final }^{2}\end{array}$ & $\mathrm{IC}^{3}$ & IC final $^{4}$ & $\begin{array}{l}\text { TOC } \\
\text { final }^{5}\end{array}$ \\
\hline 3 & 6,969 & 20,907 & 0,3136 & 0,9408 & 19,97 \\
\hline 3 & 6,333 & 18,999 & 0,8078 & 2,4234 & 16,58 \\
\hline 3 & 5,159 & 15,477 & 0,9363 & 2,8089 & 12,67 \\
\hline 3 & 3,757 & 11,271 & 0,7645 & 2,2935 & 8,98 \\
\hline 3 & 2,235 & 6,705 & 0,6417 & 1,9251 & 4,78 \\
\hline 3 & 2,032 & 6,096 & 0,5345 & 1,6035 & 4,49 \\
\hline \multirow[t]{3}{*}{3} & $\begin{array}{c}0,794 \\
2\end{array}$ & 2,3826 & 0,5229 & 1,5687 & 0,81 \\
\hline & & & & $\begin{array}{l}\text { Remoção / } \\
\text { mg L-1 }^{-1}\end{array}$ & 19 \\
\hline & & & & $\begin{array}{l}\text { Remoção / } \\
\%\end{array}$ & 96 \\
\hline
\end{tabular}

$\mathrm{TC}^{1}$ = Carbono Total; $\left.\overline{\text { TC Final }}\right|^{2}=$ Carbono Total Final; $\mid \mathrm{IC}^{3}=$ Carbono Inorgânico; IC $C^{4}$ final = Carbono Inorgânico Final; $\mathrm{TOC}^{5}=$ Carbono Orgânico Total.

Fonte - Elaborado pelo autor

Mistura (100 AR8 + 100 ppm AB113 + 100 ppm AY17) + $5 \mathrm{~g} / \mathrm{L} \mathrm{Na}_{2} \mathrm{SO}_{4}$

Semelhante ao que aconteceu com o Ácido Azul, na Mistura notamos uma remoção percentual não surpreendentemente elevada, mas quando observamos a remoção em mg.L-1 nota-se uma remoção de 65 (Tabela 9). Um valor extremamente elevado se compararmos com os valores individuais, nota-se também na mistura que o valor de carbono inorgânico subiu discretamente, acompanhando a tendência das amostragens individuais. Na Mistura a diluição referente a análise do carbono foi de 7,5 pois a concentração de corantes estava muito elevada.

Tabela 9 - Relação de carbono da amostra da Mistura.

\begin{tabular}{|c|c|c|c|c|c|}
\hline $\begin{array}{l}\text { Fator de } \\
\text { diluição }\end{array}$ & $\mathrm{TC}^{1}$ & TC final $^{2}$ & $I^{3}$ & IC final ${ }^{4}$ & TOC final ${ }^{5}$ \\
\hline 7,5 & 10,51 & 78,825 & 0,3732 & 2,80 & 76,026 \\
\hline 7,5 & 9,773 & 73,2975 & 0,6533 & 4,90 & 68,39775 \\
\hline 7,5 & 6,551 & 49,1325 & 0,5802 & 4,35 & 44,781 \\
\hline 7,5 & 4,925 & 36,9375 & 0,524 & 3,93 & 33,0075 \\
\hline 7,5 & 3,591 & 26,9325 & 0,4627 & 3,47 & 23,46225 \\
\hline 7,5 & 2,897 & 21,7275 & 0,5009 & 3,76 & 17,97075 \\
\hline \multirow[t]{3}{*}{7,5} & 1,993 & 14,9475 & 0,4801 & 3,60 & 11,34675 \\
\hline & & & & $\begin{array}{c}\text { Remoção / } \\
\mathrm{mg} \mathrm{L}^{-1}\end{array}$ & 65 \\
\hline & & & & $\begin{array}{c}\text { Remoção / } \\
\%\end{array}$ & 85 \\
\hline
\end{tabular}

TC $^{1}$ = Carbono Total; TC Final $\left.\right|^{2}=$ Carbono Total Final; IC ${ }^{3}=$ Carbono Inorgânico; IC ${ }^{4}$ final = Carbono Inorgânico Final; $\mathrm{TOC}^{5}=$ Carbono Orgânico Total.

Fonte - Elaborado pelo autor 


\section{Demanda Química de Oxigênio (DQO)}

O cálculo da Demanda Química de Oxigênio exigiu a realização de análises complementares, todas as análises foram acompanhadas da amostragem de três brancos a fim de termos um parâmetro de comparação, o branco consiste em água destilada no lugar das amostras.

Todas as amostras da DQO sofreram pouca diluição, apenas as necessárias para a realização do método da amostragem.

Ácido Vermelho 8, $100 \mathrm{ppm}+5 \mathrm{~g} / \mathrm{L} \mathrm{Na}_{2} \mathrm{SO}_{4}$

O Ácido Vermelho 8 apresentou uma redução percentual de DQO de $81 \%$ (Tabela 10) representando uma remoção bruta de $86 \mathrm{mg} \mathrm{L}^{-1}$, durante o processo de análise o valor do DQO sofreu oscilações, demonstrando que o sistema de análise sofreu interferências externas, fica claro que as interferências foram sentidas nas amostras dois, três e quatro, porém o resultado final de remoção ficou dentro do esperado para a amostragem, demonstrando que a interferência não impactou o resultado final da amostra.

Tabela 10 - Demanda Química de Oxigênio após o experimento do Ácido Vermelho 8.

\begin{tabular}{|c|c|c|c|c|c|}
\hline Branco & 3786 & 3798 & 3788 & \multicolumn{2}{|c|}{3790,667} \\
\hline Frequência & \multicolumn{5}{|c|}{273,7956} \\
\hline Amostra & $\mathrm{D}(\mathrm{ml})$ & \multicolumn{2}{|c|}{ Titulação } & Média & $\mathrm{mg} \mathrm{O}_{\mathrm{L}^{-1}}$ \\
\hline 0 & 1 & 3398 & 3406 & 3402 & 106 \\
\hline 1 & 1 & 3570 & 3368 & 3469 & 88 \\
\hline 2 & 1 & 3662 & 3662 & 3662 & 35 \\
\hline 3 & 1 & 3712 & 3612 & 3612 & 49 \\
\hline 4 & 1 & 3528 & 3442 & 3485 & 84 \\
\hline 5 & 1 & 3506 & 3560 & 3533 & 71 \\
\hline \multirow[t]{3}{*}{6} & 1 & 3748 & 3682 & 3715 & 21 \\
\hline & & & & $\begin{array}{c}\text { Remoção / } \\
\text { mg L }^{-1}\end{array}$ & 86 \\
\hline & & & & $\begin{array}{c}\text { Remoção / } \\
\%\end{array}$ & 81 \\
\hline
\end{tabular}

Fonte - Elaborado pelo autor

A Figura 12 referente à amostragem do Ácido Vermelho não demonstrou uma queda exponencial, os pontos 2, 4 e 5 sofreram alguma influência que não foi possível detectar.

Ácido Azul 113, $100 \mathrm{ppm}+5 \mathrm{~g} / \mathrm{L} \mathrm{Na}_{2} \mathrm{SO}_{4}$

O Ácido Azul 113 também apresentou uma interferência externa durante o experimento, esta interferência comprometeu o resultado da amostra cinco, esta influência fez com que o valor de DQO obtido ficasse bem acima do valor esperado (Tabela 11). Mesmo com essa pontual interferência o valor de remoção apresentou percentual de 73 \% e valor bruto de 117 , demonstrando que a análise foi eficiente no que se propôs realizar. 
Figura 12 - Decaimento da demanda Química de Oxigênio do Ácido Vermelho 8 durante o experimento.

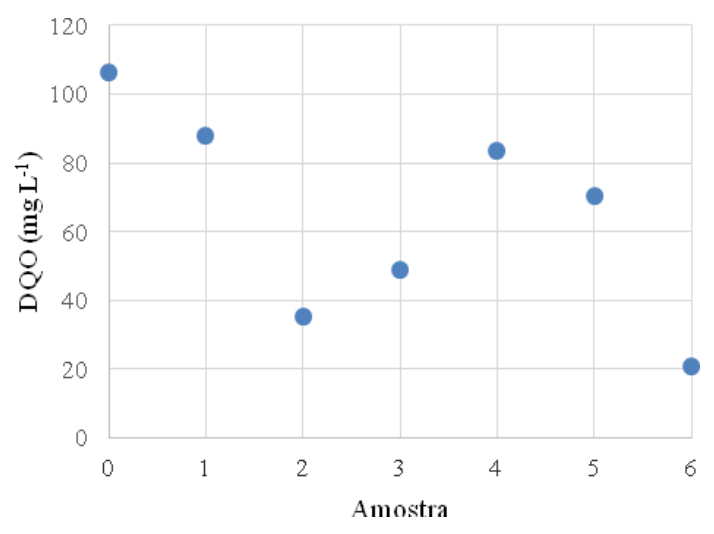

Fonte - Elaborado pelo autor

Tabela 11 - Demanda Química de Oxigênio após o experimento do Ácido Azul 113.

\begin{tabular}{|c|c|c|c|c|c|}
\hline \multirow{2}{*}{$\begin{array}{l}\text { Branco } \\
\text { Frequência }\end{array}$} & 3896 & 3944 & 3898 & \multicolumn{2}{|c|}{3912,667} \\
\hline & \multicolumn{5}{|c|}{273,7956} \\
\hline Amostra & $\mathrm{D}(\mathrm{ml})$ & \multicolumn{2}{|c|}{ Titulação } & Média & $\underset{\mathrm{L}^{-1}}{\mathrm{mg} \mathrm{O}_{2}}$ \\
\hline 0 & 1 & 3328 & 3328 & 3328 & 160 \\
\hline 1 & 1 & 3410 & 3464 & 3437 & 130 \\
\hline 2 & 1 & 3486 & 3518 & 3502 & 112 \\
\hline 3 & 1 & 3632 & 3586 & 3609 & 83 \\
\hline 4 & 1 & 3668 & 3722 & 3695 & 60 \\
\hline 5 & 1 & 3490 & 3504 & 3497 & 114 \\
\hline \multirow[t]{3}{*}{6} & 1 & 3760 & 3748 & 3754 & 43 \\
\hline & & & & $\begin{array}{l}\text { Remoção } \\
/ \mathrm{mg} \mathrm{L}^{-1}\end{array}$ & 117 \\
\hline & & & & $\begin{array}{c}\text { Remoção } \\
/ \%\end{array}$ & 73 \\
\hline
\end{tabular}

Fonte - Elaborado pelo autor

A Figura 13 referente a amostragem do Ácido Azul 113 demonstrou uma queda exponencial com exceção do ponto 5 que sofreu alguma influência externa que não foi possível detectar. 
Figura 13 - Decaimento da demanda Química de Oxigênio do Ácido Azul 113 durante o experimento.

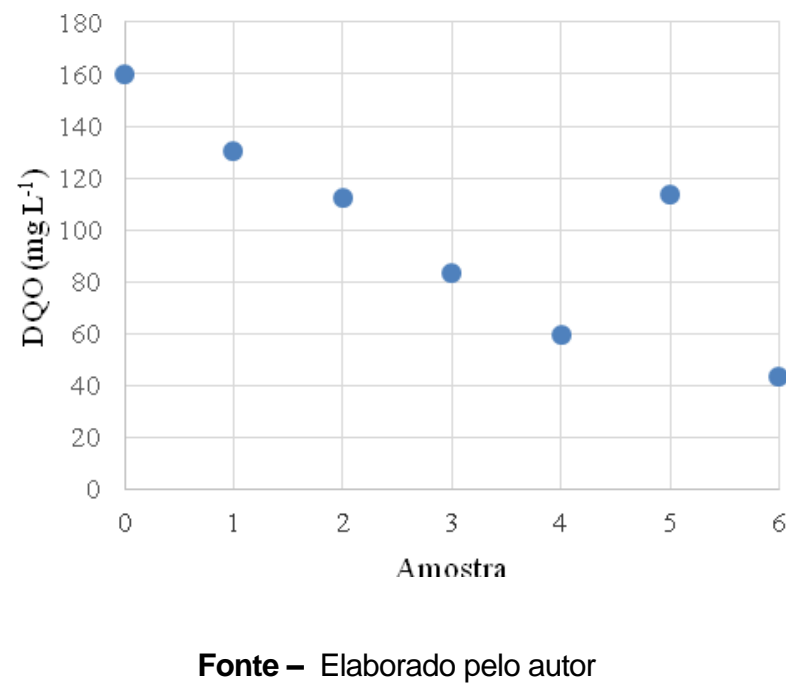

Ácido Amarelo 17, $100 \mathrm{ppm}+5 \mathrm{~g} / \mathrm{L} \mathrm{Na}_{2} \mathrm{SO}_{4}$

O Ácido Amarelo 17 foi a amostragem que apresentou os melhores valores referentes ao DQO, apresentando uma remoção de $104 \%$, que pode ser visualizado na Tabela 12, considerando o erro do método temos que a DQO apresentou uma remoção de $100 \%$, a remoção bruta ficou em $97 \mathrm{mg} \mathrm{L}^{-1}$, novamente considerando o erro temos uma remoção total. Os valores também apresentaram um padrão de decaimento.

Tabela 12 - Demanda Química de Oxigênio após o experimento do Ácido Amarelo 17.

\begin{tabular}{|c|c|c|c|c|c|}
\hline Branco & 3808 & 3832 & 3830 & \multicolumn{2}{|c|}{3831} \\
\hline Frequência & \multicolumn{5}{|c|}{273,7956} \\
\hline Amostra & $\mathrm{D}(\mathrm{ml})$ & \multicolumn{2}{|c|}{ Titulação } & Média & $\mathrm{mg} \mathrm{O}_{2} \mathrm{~L}^{-1}$ \\
\hline 0 & 1 & 3492 & 3488 & 3490 & 93 \\
\hline 1 & 1 & 3634 & 3588 & 3588 & 67 \\
\hline 2 & 1 & 3656 & 3646 & 3651 & 49 \\
\hline 3 & 1 & 3620 & 3662 & 3662 & 46 \\
\hline 4 & 1 & 3680 & 3718 & 3699 & 36 \\
\hline 5 & 1 & 3706 & 3726 & 3716 & 31 \\
\hline \multirow[t]{3}{*}{6} & 1 & 3844 & 3842 & 3843 & -3 \\
\hline & & & & $\begin{array}{c}\text { Remoção / } \\
\text { mg L-1 }^{-1}\end{array}$ & 97 \\
\hline & & & & $\begin{array}{c}\text { Remoção / } \\
\%\end{array}$ & 104 \\
\hline
\end{tabular}

Fonte - Elaborado pelo autor 
A Figura 14 referente a amostragem do Ácido Amarelo 17 demonstrou uma queda exponencial demonstrando a queda relativamente constante dos valoras de DQO amostrada.

Figura 14 - Decaimento da demanda Química de Oxigênio do Ácido Amarelo 17 durante o experimento.

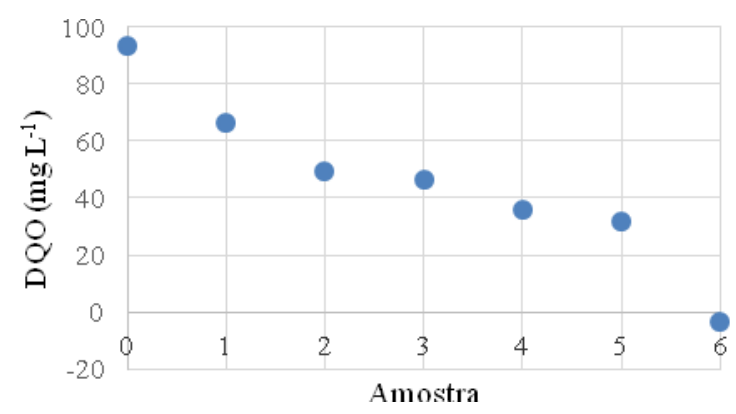

Fonte - Elaborado pelo autor

Mistura (100 ppm AR8 + 100 ppm AB113 + 100 ppm AY17) + 5 g/L Na $2 \mathrm{SO}_{4}$

A Mistura foi a amostragem que apresentou a maior taxa de remoção quando consideramos 0 valor bruto, este valor ficou na casa de $278 \mathrm{mg} \mathrm{L}^{-1} \mathrm{em}$ seis horas de experimento, em percentual (Tabela 13) este valor representa cerca de $85 \%$, (Figura 15) um valor bastante considerável quando é levado em consideração que a concentração na mistura foi maior que nas outras amostras, por conter 100 ppm de cada corante.

Tabela 13 - Demanda Química de Oxigênio após o experimento da Mistura.

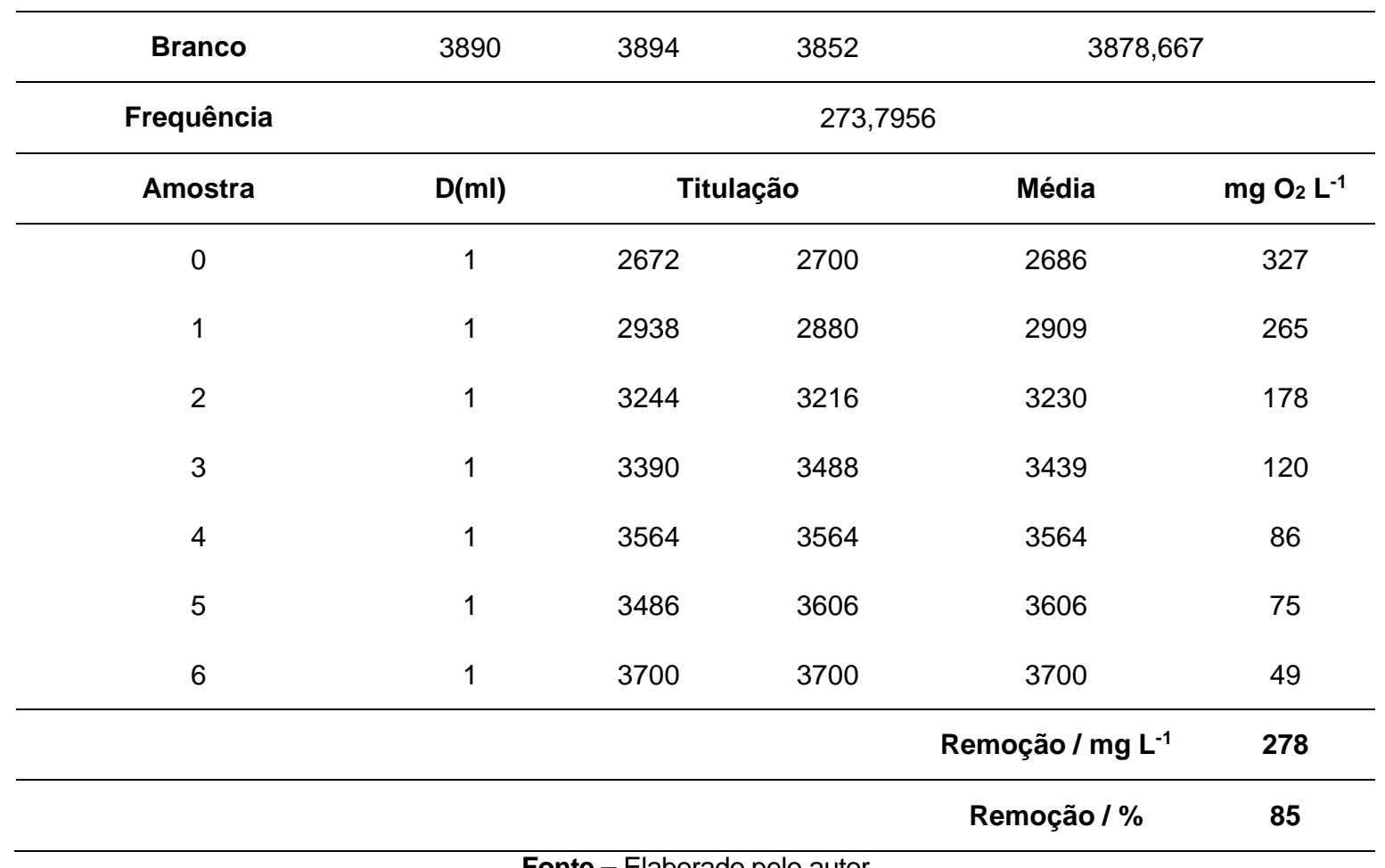

Fonte - Elaborado pelo autor

A Figura 15 referente à amostragem da Mistura demonstrou uma queda exponencial, demonstrando a queda relativamente constante dos valoras de DQO amostrada. 
Figura 15 - Decaimento da demanda Química de Oxigênio da Mistura durante o experimento.

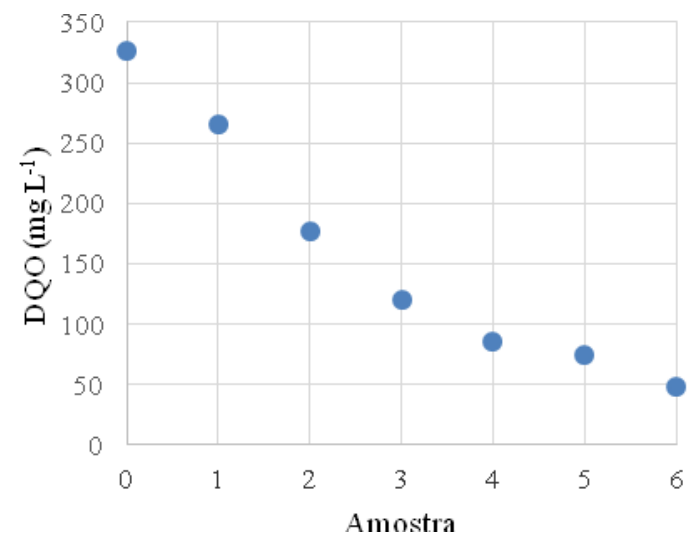

Fonte - Elaborado pelo autor

\section{CONSIDERAÇÕES FINAIS}

O processo eletroquímico para tratamento de poluentes químicos representa uma nova concepção em tratamento de rejeitos aquosos. Os resultados alcançados com a aplicação desta técnica indicam que esta metodologia é eficiente para tratar corantes orgânicos. Diante destes resultados, o processo eletroquímico apresenta-se como uma técnica com real possibilidade de aplicação em grande escala, podendo também ser empregada como prétratamento e contribuir de maneira acentuada para a biodegradabilidade dos efluentes têxteis.

Porém, o processo de oxidação anódica se mostra uma opção bastante onerosa, pois a utilização da placa de DDB e da energia elétrica aumentam consideravelmente os custos, sendo assim, tornando-se usual quando utilizado como um pré-tratamento para o efluente, viabilizando e facilitando tratamentos convencionais subsequentes.

Por ser uma opção eficiente, porém dispendiosa, o estudo posterior de novas técnicas e novos materiais se mostra viável e promissor, portanto, este trabalho serve como incentivo para futuras pesquisas.

\section{AGRADECIMENTOS}

A Universidade da Beira Interior localizado no município de Covilhã em Portugal e ao Banco Santander S/A pela bolsa concedida e a Prof. Dra. Ana Carrera Lopes.

\section{REFERÊNCIAS}

ASSOCIAÇÃO BRASILEIRA DA INDÚSTRIA QUÍMICA: ABIQUIM. História. Disponível em: <http://abiquim.org.br/corantes/cor_historia.asp>. Acesso em: 02 de out. de 2014.

BEZERRA ROCHA, J.H. Tecnologia eletroquímica como tratamento alternativo de efluentes têxteis sintéticos utilizando ânodos de platina e diamante. 2011. 89 f. Dissertação (Mestrado em Química)- Programa de Pós-Graduação em Química, Centro de Ciências Exatas e da Terra, Universidade Federal do Rio Grande do Norte. Natal, 2011.

CATANHO, M.; MALPASS, G. R. P.; MOTHEO. A. J. Avaliação dos Tratamentos Eletroquímico e Fotoeletroquímico na Degradação de Corantes Têxteis. Química Nova, São Paulo, v. 29, n. 5, p. 983-989, 2006. https://doi.org/10.1590/S0100-40422006000500018 
CETESB - COMPANHIA AMBIENTAL DO ESTADO DE SÃO PAULO. Demanda Química de Oxigênio (DQO). São Paulo. Disponível em: <http://www.cetesb.sp. gov.br/userfiles/file/agua/aguas-superficiais/aguas-interiores /variaveis/aguas/ variaveis_quimicas/demanda_quimica_de_oxigenio.pdf>. Acesso em: 02 de out. de 2014.

CARVALHO, C.; FERNANDES, A.; LOPES, A.; PINHEIRO H.; GONÇALVES, I.

Electrochemical degradation of C. I. Acid Orange 7. Dyes and Pigments, Volume 61, Issue 3, Junho 2004, Páginas 287-296, ISSN 0143-7208. Disponível em:

<http://www.sciencedirect.com/science/article/pii/S01437208030023 41 >. Acesso em: 02 de out. de 2014.

https://doi.org/10.1016/j.dyepig.2003.11.008

ELIZALDE-GONZÁLEZ, M.P.; MATTUSCH, J.; EINICKE, W.D.; WENNRICH, R. Sorption on natural solids for arsenic removal. Chemical Engineering Journal, 81: 187-195, 2001. https://doi.org/10.1016/S1385-8947(00)00201-1

FORGACS, E., CSERHÁTI, T., OROS, G. Removal of synthetic dyes from wastewaters: A review, Environment International, v. 30 n. 7, p. 953-971, 2004. Disponível em: <http://www.sciencedirect.com/science/article/pii/S0160412004000340>. Acesso em: 02 de out. de 2014.

https://doi.org/10.1016/..envint.2004.02.001

FORNAZARI, A. L. T., MALPASS G. R. P., MIWA, D. W., MOTHEO A. J. Aplicação da Degradação Eletroquímica de Efluentes Composto por Misturas de Fenol - Formaldeído. International Workshop. key elements for a sustainable world: energy, water and climate change. São Paulo, Brazil, May 20th-22nd. 2009.

GOMES, L. Degradação eletroquímica do corante têxtil Alaranjado Remazol 3R utilizando diferentes eletrodos. 2009. Tese (Doutorado em Físico-Química) - Instituto de Química de São Carlos, Universidade de São Paulo, São Carlos, 2009. Disponível em:

$<$ http://www.teses.usp.br/teses/disponiveis/75/75131/ tde-11032010-105633/>. Acesso em: 25 de nov. de 2014.

GUARATINI, C. C. I.; ZANONI, M.V.B. Corantes têxteis. Química Nova, São Paulo, v. 23, n. 1, p. $71-78$, jan., 2000

https://doi.org/10.1590/S0100-40422000000100013

HANGZHOU DIMACHEMA IMP \& EXP CO, LTD. Acid Yellow 17 for Textile. Disponível em: <http://pt.made-in-china.com/co_dimachema1/product_Acid-Yellow-17-for-

Textile_eiouooseg.html>. Acesso em: 02 de out. de 2014.

HIGA, M. C. Aplicação de ensaios de toxicidade na avaliação da eficiência da radiação ionizante e da adsorção em Zeólitas para o tratamento de efluentes coloridos. 2008. f. 93. Dissertação (Mestrado em Ciência na área de Tecnologia Nuclear) - Instituto de pesquisas Energéticas e Nucleares, Universidade de São Paulo, São Paulo, 2008. Disponível em: <http://www.teses.usp.br/teses/disponiveis/85/85131/tde-15092009-173013/pt-br.php >. Acesso em: 8 out. de 2014 .

MARTINEZ-HUITLE, C.A.; FERRO, S. Electrochemical oxidation of organic pollutants for the wastewater treatment: Direct and indirect processes. Chem. Soc. Rev., 35, 1324-1340, 2006. https://doi.org/10.1039/B517632H

MARTINEZ-HUITLE, C.A., BRILLAS, E. Decontamination of wastewaters containing synthetic organic dyes by electrochemical methods. A general review. Appl. Catal. B: Environmental. 87, 105-145, 2009.

https://doi.org/10.1016/j.apcatb.2008.09.017

PANIZZA, M.; CERISOLA, G. Electrochemical processes for the treatment of organic pollutants. Chem. Rev., 109, 6541-6569, 2009. 


\section{https://doi.org/10.1021/cr9001319}

PROGRAMA AGUA AZUL. Nitrogênio Total. Rio Grande do Norte. Disponível em: $<$ http://www.programaaguaazul.rn.gov.br/indicadores_06.php>. Acesso em: 02 de out. de 2014.

SHAOXING SUNDAY TEXTILE \& CHEMICAL CO. LTD. Product: Acid blue, corantes, acid blue 113. Disponível em: <http://portuguese.alibaba.com/product-gs/acid-blue-dyes-acid-blue113-1174836513.html?s=p>. Acesso em: 02 de out. de 2014.

SIGMA ALDRICH. Product: Acid Blue 113. Disponível em: <http://www.sigmaaldrich. com/catalog/product/aldrich/210439? lang=pt\&region=BR $>$. Acesso em: 02 de out. de 2014.

Product: Acid Red 8. Disponível em: <http://www.sigmaaldrich. com/catalog/product/aldrich/214523?lang=pt\&region=BR>. Acesso em: 02 de out. de 2014.

Product: Acid Yellow 17. Disponível em: <http://www.sigma aldrich.com/catalog/product/sial/201987?lang=pt\&region=BR>. Acesso em: 02 de out. de 2014.

Recebido em: 04/07/2018

Aceito para publicação em: 25/01/2019 